\title{
Mengukur Tingkat Reusability dan Efficiency dari Kode Program dengan Pendekatan Fuzzy Logic
}

\author{
Arwin Halim ${ }^{1}$, Alex Xandra Albert $\mathrm{Sim}^{2}$, Gabyola $^{3}$, Hartono ${ }^{4}$ \\ Program Studi Teknik Informatika, STMIK Mikroskil \\ Jl. Thamrin No. 122, 124, 140 Medan 20212 \\ Medan, Indonesia

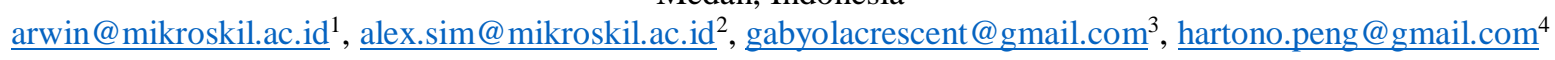

\begin{abstract}
Abstrak-Kode program merupakan salah satu keluaran dalam proses pengembangan sistem. Kualitas dari kode program dapat digunakan untuk merepresentasikan kualitas sistem secara keseluruhan. Salah satu cara untuk mengukur kualitas dari program adalah menghitung nilai metrik kualitas. Nilai-nilai dari metrik kualitas sulit dimengerti karena memiliki makna tersendiri dan bersifat tidak tentu. Pada penelitian ini, faktor kualitas eksternal berupa reusability dan efficiency diukur melalui pendekatan fuzzy logic Mamdani. Masukan dari fuzzy logic diperoleh dari hasil perhitungan CK Metrics dari kode program berorientasi objek. Keluaran dari penelitian berupa aplikasi yang mampu menghitung nilai metrik kualitas eksternal dengan menghasilkan nilai kuantitatif dan kualitatif dari kode program, sehingga dapat digunakan untuk membandingkan dua atau lebih kode program.
\end{abstract}

Keywords—efficiency; fuzzy logic; kode program; reusability

\section{PENDAHULUAN}

Berbagai usaha telah dilakukan untuk menyediakan pedoman yang baik dalam mengukur kualitas perangkat lunak menunjukkan pentingnya peran perangkat lunak dalam kehidupan sehari-hari [1]. Kualitas perangkat lunak dapat diukur menggunakan software quality metrics. Hasil pengukuran tersebut digunakan untuk menghitung kualitas eksternal perangkat lunak, seperti maintainability, flexibility, testability, reusability, reliability, efficiency dan usability [2]. Faktor kualitas eksternal menunjukkan aspek kualitas tertentu yang dapat dinilai dari perangkat lunak. Penelitian ini berfokus pada reusability dan efficiency. Reusability menunjukkan kemampuan bagian program yang dapat digunakan kembali. Efficiency menunjukkan daya guna program terhadap sumber daya dari kode program untuk menjalankan suatu fungsi [2]. Perangkat lunak berorientasi objek yang berkualitas ditunjukkan dengan nilai reusability dan efficiency yang tinggi.

Software quality metrics dapat digunakan untuk mengukur kualitas perangkat lunak terstruktur dan berorientasi objek. Kualitas perangkat lunak terstruktur dihitung menggunakan metrik tradisional seperti Lines of Codes (LOC), Cyclomatic
Complexity dan lain-lain. Pada perangkat lunak berorientasi objek, pengukuran terpusat pada bagian-bagian dari class seperti data dan prosedur. Menurut Prather dan Weyuker, penilaian kualitas berorientasi objek lebih mudah dinilai secara matematis dibandingkan dengan pemrograman terstruktur [3].

Berbagai metrik untuk pengukuran program berorientasi objek telah diusulkan, seperti Chidamber-Kemerer Metrics (CK Metrics) [3], Lorenz-Kidd Metrics, MOOD, dan QMOOD. Salah satu OO Metrics yang banyak digunakan adalah CK Metrics. Penelitian Mago dan Kaur [4] menunjukkan nilai-nilai dari $\mathrm{CK}$ Metrics dapat digunakan untuk mengukur kualitas eksternal perangkat lunak. Penelitian Laird dan Brennan [1] menunjukkan CK Metrics adalah metrik yang berguna jika didefinisikan dengan tepat. Permasalahannya adalah sulitnya mengartikan nilai-nilai dari CK Metrics dengan tepat. Penelitian Stamelos dkk [5] menggunakan pendekatan statistik untuk menentukan kualitas eksternal berdasarkan metrik tradisional pada perangkat lunak berkode bebas seperti testability, simplicity, readability dan self-descriptiveness. Penelitian Mago dkk [6] mengusulkan pendekatan fuzzy dengan kurva trapesium untuk menentukan nilai tunggal dari kualitas eksternal perangkat lunak berorientasi objek.

Pada penelitian ini, nilai metrik dihitung berdasarkan kode program perangkat lunak berorientasi objek dengan CK Metrics. Program perangkat lunak berorientasi objek dipilih karena pendekatan ini telah berkembang dan digunakan untuk mengembangkan sistem berskala besar sesuai dengan batasan waktu dan biaya [7]. Nilai metrik kualitas digunakan sebagai masukan pada Fuzzy Inference System untuk mendapatkan kesimpulan berupa nilai yang menunjukkan faktor kualitas reusability dan efficiency. Pendekatan fuzzy mampu menarik kesimpulan yang lebih bervariatif [8], sehingga memungkinkan pengembang untuk mengukur kualitas eksternal perangkat lunak dengan tepat.

Sistematika penulisan dimulai dari pendahuluan. Bagian kedua menjelaskan landasan teori yang digunakan dalam penelitian dan dilanjutkan dengan penjabaran metode 
penelitian. Bagian keempat menunjukkan hasil dan pengujian dari penelitian. Pada bagian terakhir berisi kesimpulan.

\section{Tinjauan Pustaka}

\section{A. Chidamber-Kemerer Metrics}

Chidamber-Kemerer Metrics (CK Metrics) [3] merupakan salah satu Object Oriented Metric yang dapat digunakan untuk mengukur kualitas desain sebuah program. CK Metrics diusulkan oleh Shyam R. Chidamber dan Chris F. Kemerer pada tahun 1994. CK Metrics terdiri dari 6 metrik yang dijadikan parameter dalam mengukur kualitas program. Keenam metrik tersebut adalah:

\section{Weight Method per Class (WMC).}

WMC merupakan metrik yang berfokus pada kompleksitas dari method pada sebuah class. Kompleksitas dapat dihitung dengan rumus cyclomatic complexity. WMC menjumlahkan semua nilai kompleksitas dalam semua method di dalam sebuah class seperti Persamaan 1.

$$
W M C=\sum_{\mathrm{i}=1}^{n} c_{\mathrm{i}}
$$

dimana:

$\mathrm{n}=$ jumlah method dalam sebuah class

ci $=$ cyclomatic complexity dari sebuah method $i$

2. Depth of Inheritance Tree (DIT)

DIT merupakan jarak node ke root dalam class yang memiliki inheritance atau dengan kata lain berapa banyak inheritance yang digunakan dalam class tersebut. Semakin tinggi nilai DIT menunjukan desain yang lebih kompleks dan reusability yang lebih tinggi, tetapi nilai DIT yang tinggi juga menunjukkan tingkat efficiency yang rendah.

\section{Number of Children (NOC)}

NOC merupakan jumlah subclass langsung yang terdapat dalam sebuah class. NOC mengukur berapa banyak subclass yang meng-inherit method dari parent class. Nilai NOC yang tinggi tidak hanya menunjukkan reusability yang tinggi, tetapi juga kemungkinan adanya subclassing yang tidak tepat yang mengurangi nilai efficiency.

\section{Coupling Between Object Classes (CBO)}

CBO menghitung coupling non-inheritance antara suatu class terhadap class lain, contohnya suatu class menggunakan method atau variabel dari class lain. Jika suatu class memanggil beberapa method maupun variabel dari sebuah class lain, maka jumlah relasi tetap dihitung
1. Nilai CBO yang tinggi menunjukkan kurangnya reusability, efficiency, dan maintainability.

\section{Response For a Class (RFC)}

RFC adalah himpunan method yang dapat dijalankan sebagai respon dari objek dalam sebuah class. RFC dihitung menggunakan Persamaan 2.

$$
R F C=\{M\} \cup\left\{R_{i}\right\}
$$

dimana:

$\mathrm{M}=$ himpunan method yang dipanggil dalam class

$\mathrm{R}=$ himpunan method yang dipanggil oleh method $\mathrm{i}$

\section{Lack of Cohesion of Methods (LCOM)}

LCOM menghitung selisih antara jumlah method dalam sebuah class yang memiliki parameter atau return type. Semakin besar nilai LCOM, semakin besar pula kompleksitas class tersebut dan berpengaruh pada rendahnya tingkat reusability dan efficiency. LCOM dapat dihitung sesuai Persamaan 3 dan 4.

$$
\sigma()=\left\{I_{1}\right\} \cap\left\{I_{2}\right\}
$$

dimana:

$\mathrm{I} 1=$ himpunan parameter atau return type yang dimiliki method 1

$\mathrm{I} 2=$ himpunan parameter atau return type yang dimiliki method 2

Catatan: $\sigma()$ dilakukan terhadap semua perpaduan method dalam satu class.

$$
\text { LCOM }=\left\{\begin{aligned}
0, & P<Q \\
P-Q, & P \geq Q
\end{aligned}\right.
$$

dimana:

$\mathrm{P}=$ jumlah $\sigma()$ dengan nilai 0

$\mathrm{Q}=$ jumlah $\sigma($ ) dengan nilai lebih dari 0

CK Metrics dapat menilai kompleksitas program, besar class, penggunaan inheritance, perpaduan dalam class, dan hubungan dengan class lainnya. Sedangkan hubungan metrikmetrik tersebut dengan faktor kualitas eksternal perangkat lunak dapat dilihat dalam Tabel 1 [4]. 
Tabel 1. Hubungan CK Metrics dan Faktor Kualitas Eksternal

\begin{tabular}{|c|c|c|}
\hline CK Metrics & Kualitas Eksternal & Konsep OOP \\
\hline WMC & $\begin{array}{c}\text { Maintainability, } \\
\text { Understandability, Reusability }\end{array}$ & Class/Method \\
\hline RFC & $\begin{array}{r}\text { Understandability, Testability, } \\
\text { Maintainability }\end{array}$ & Class/Method \\
\hline LCOM & Reusability, Efficiency & Class/Method \\
\hline CBO & Reusability, Efficiency & Coupling \\
\hline DIT & $\begin{array}{r}\text { Reusability, Efficiency, } \\
\text { Testability }\end{array}$ & Inheritance \\
\hline NOC & $\begin{array}{r}\text { Reusability, Efficiency, } \\
\text { Testability }\end{array}$ & Inheritance \\
\hline
\end{tabular}

\section{B. Fuzzy Logic}

Sistem pengambilan keputusan konvensional menyimpulkan suatu nilai dengan memasukannya ke dalam suatu himpunan tegas (crisp sets) yang memiliki fungsi keanggotaan dengan dua kemungkinan nilai keanggotaan, yaitu 1 yang berarti nilai tersebut merupakan anggota dari himpunan itu, dan 0 yang berarti nilai tersebut bukan anggota dari himpunan itu. Sedangkan dalam himpunan fuzzy, fungsi keanggotaannya bisa memiliki nilai dengan range 0 sampai 1 . Perhitungan nilai keanggotaan dalam himpunan fuzzy dapat direpresentasikan dalam beberapa cara, seperti representasi linear, kurva trapesium, kurva segitiga, dan lain-lain. Gambar 1 merepresentasikan nilai keanggotaan dengan kurva segitiga pada fuzzy logic.

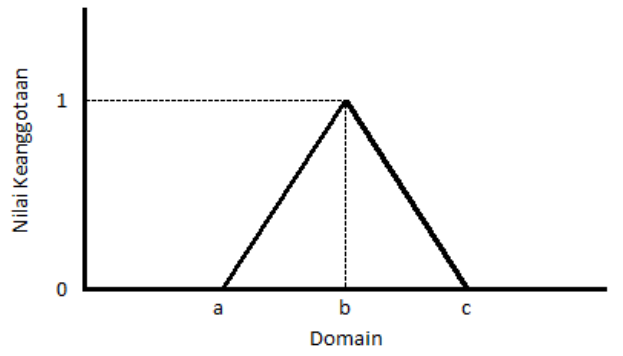

Gambar 1. Nilai Keanggotaan dengan Kurva Segitiga

Perhitungan nilai keanggotaan untuk kurva segitiga dapat dilihat di Persamaan 5.

$$
f(x)=\left\{\begin{aligned}
0, & x \leq a \text { atau } x \geq c \\
\frac{x-a}{b-a}, & a \leq x \leq b \\
\frac{d-x}{d-c}, & x \geq c
\end{aligned}\right.
$$

Beberapa himpunan fuzzy, dapat digabung menggunakan operator-operator dasar seperti operator AND dan operator OR. Sistem fuzzy menggunakan fungsi implikasi dan aturan fuzzy sebagai dasar dalam pengambilan keputusan. Bentuk umum dari aturan yang digunakan adalah IF-THEN rule. Untuk mendapat nilai output, fungsi implikasi digunakan untuk memotong kurva fungsi keanggotaan output berdasarkan aturan-aturan fuzzy yang ada. Salah satu cara fungsi implikasi yang dapat digunakan adalah metode Min (minimum). Metode ini memotong kurva fungsi keanggotaan output berdasarkan himpunan input yang memiliki nilai keanggotaan terkecil (operator AND).

Metode Mamdani [7] diperkenalkan oleh Ebrahim Mamdani pada tahun 1975. Metode ini sering juga disebut metode Max-Min, karena menggunakan komposisi aturan Max (operator OR) dan fungsi implikasi Min (operator AND). Tahapan-tahapan dalam metode ini antara lain:

a. Pembentukan himpunan fuzzy

Pada metode ini, variabel input dan output dinyatakan ke dalam himpunan fuzzy.

b. Aplikasi fungsi implikasi

Fungsi implikasi yang digunakan dalam metode ini adalah Min

c. Komposisi aturan

Komposisi aturan adalah penggabungan dari kurvakurva yang didapat dari hasil perhitungan fungsi implikasi. Pada metode ini yang digunakan adalah metode Max (maximum), oleh karena itu metode Mamdani juga disebut dengan metode Max-Min. Metode Max mengambil nilai keanggotaan tertinggi dari setiap kurva hasil perhitungan fungsi implikasi kemudian mengaplikasikannya menjadi sebuah fungsi keanggotaan dengan menggunakan operator OR, atau dapat ditulis dalam Persamaan 6.

$$
\mu_{s f}\left[X_{i}\right] \leftarrow \max \left(\mu_{s f}\left[X_{i}\right], \mu_{k f}\left[X_{i}\right]\right)
$$

dimana:

$\mu_{\mathrm{sf}}[\mathrm{xi}]=$ nilai keanggotaan input sampai aturan ke- $i$ $\mu_{\mathrm{kf}}[\mathrm{xi}]=$ nilai keanggotaan output aturan ke- $i$

d. Defuzzification

Defuzzification adalah proses untuk mendapatkan sebuah nilai tunggal dari nilai-nilai keanggotaan yang diperoleh dari komposisi aturan fuzzy. Ada beberapa metode yang dapat digunakan dalam defuzzification, antara lain metode centroid, weighted average, bisektor, mean of maximum, largest of maximum, dan smallest of maximum. Metode yang digunakan dalam penelitian ini adalah metode weighted average yang dihitung menggunakan Persamaan 7.

$$
Y=\frac{\sum C C i \times T i}{\sum T i}
$$

dimana: 


$$
\begin{array}{ll}
\mathrm{Y} & =\text { nilai tunggal hasil defuzzification } \\
\mathrm{CCi} & =\text { nilai tengah kurva output }-\mathrm{i} \\
\mathrm{Ti} & =\text { nilai keanggotaan kurva output }-\mathrm{i}
\end{array}
$$

\section{METODOLOGI PENELITIAN}

Tahapan pengukuran faktor kualitas eksternal berupa reusability dan efficiency adalah:

1. Pengumpulan data.

Pada tahapan ini dikumpulkan proyek-proyek C\# berkode bebasyang memiliki versi yang berbeda dari berbagai sumber. Proyek-proyek inilah yang akan diukur nilai kualitasnya.

2. Analisis Proses

Pada tahapan ini, dilakukan perhitungan nilai CK Metrics untuk setiap class pada proyek perangkat lunak, kemudian hasil pengukuran digunakan sebagai masukan pada Fuzzy Inference System untuk mengetahui nilai kualitas eksternal proyek. Faktor kualitas eksternal reusability dipengaruhi oleh metrik WMC, LCOM, CBO, DIT dan NOC. Faktor kultias eksternal efficiency dipengaruhi oleh metrik LCOM, CBO, DIT dan NOC. Tahapan dalam metode Mamdani Fuzzy Inference System yang diadopsi adalah:

a. Pembentukan himpunan dan aturan fuzzy. Dalam tahap ini dibentuk himpunan fuzzy dan kurva keanggotaan dari tiap-tiap input dan output. Setiap input memiliki empat nilai yaitu very low, low, medium, dan high. Sedangkan setiap output memiliki tiga nilai yaitu low, medium, dan high [4]. Selain itu juga dibentuk himpunan fuzzy berdasarkan pengaruh metrik-metrik CK Metrics terhadap reusability, dan efficiency.

b. Aplikasi fungsi implikasi. Pada tahap ini dicari nilai keanggotaan setiap input mengunakan fungsi kurva segitiga. Gambar 2 dan Gambar 3 menunjukkan contoh kurva keanggotaan untuk metrik kualitas dan faktor kualitas eksternal.

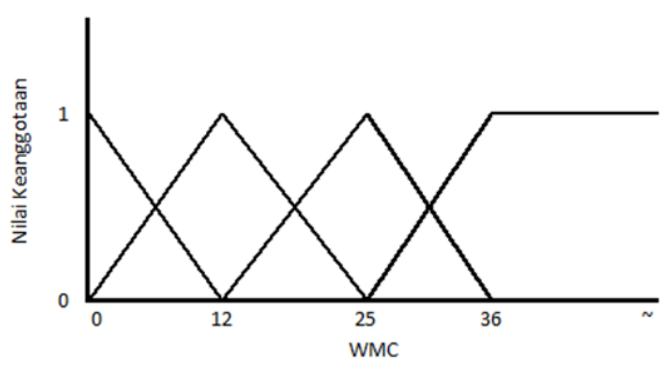

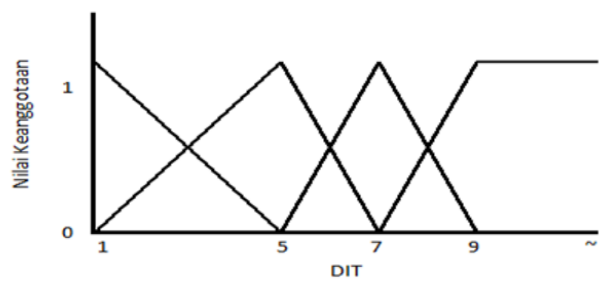
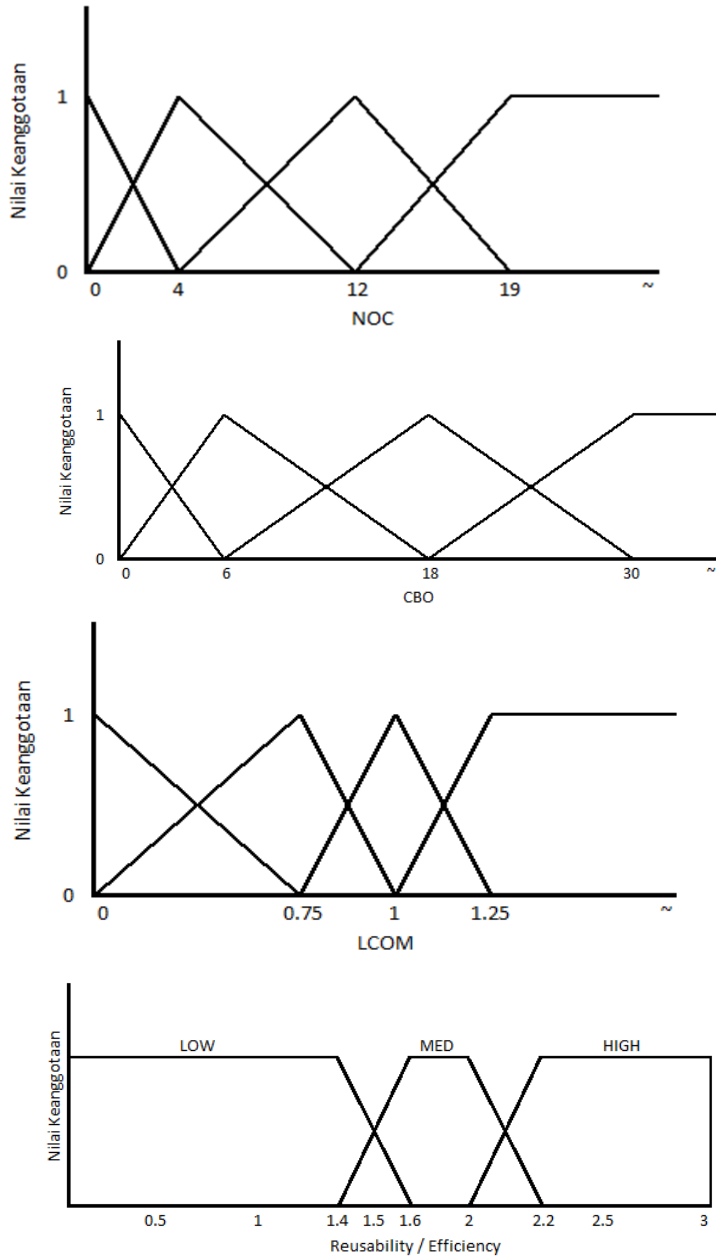

Gambar 2. Nilai Keanggotaan untuk Metrik WMC, DIT, NOC, CBO, LCOM, Reusability dan Efficiency

c. Komposisi Aturan. Komposisi aturan memotong kurva output sesuai dengan penggabungan hasil yang didapat dari tahap sebelumnya menggunakan metode $\max$

d. Defuzzification. Proses mendapat sebuah nilai tunggal dari hasil yang sudah ada dengan menggunakan metode weighted average.

3. Pengembangan Aplikasi

Pada tahap ini dilakukan pengembangan aplikasi pengukuran kualitas eksternal reusability dan efficiency dengan menggunakan bahasa pemrograman $\mathrm{C \#}$. 
4. Pengujian

Pada tahap ini dilakukan pengujian aplikasi yang telah dikembangkan dengan aplikasi berkode sumber bebas yang telah dikumpulkan.

\section{HASIL DAN PENGUJIAN}

A. Hasil

Tampilan utama dari aplikasi yang dikembangkan menerima masukan berupa solution dari proyek dengan bahasa pemrograman C\#. Gambar 3 menunjukkan contoh keluaran dari perhitungan nilai CK Metrics dan metrik kualitas eksternal reusability dan efficiency.

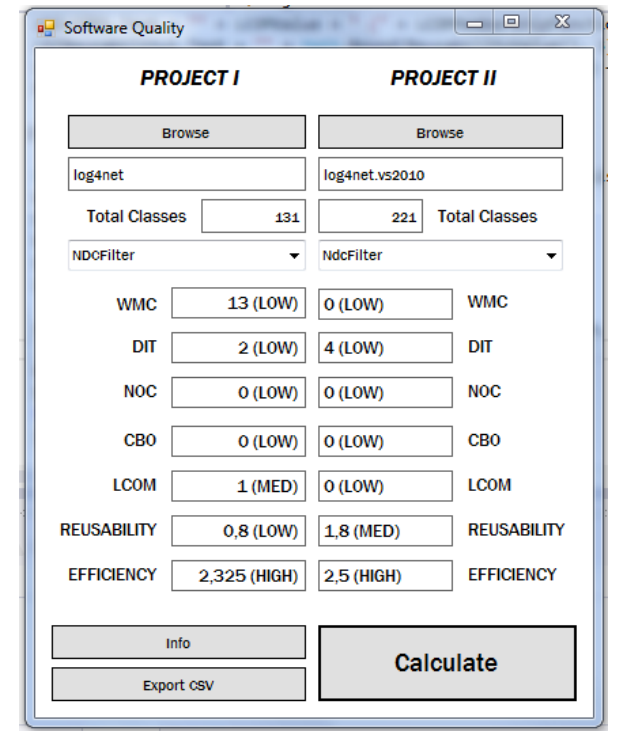

Gambar 3. Tampilan Utama Aplikasi Pengukuran Kualitas Reusability dan Efficiency dengan Fuzzy Logic

\section{B. Pengujian}

Data pengujian yang digunakan adalah Apache Avro C\# API. Perangkat lunak Avro merupakan salah satu proyek Apache untuk menserialisasi data. Serialisasi data adalah proses mengubah object menjadi bentuk biner atau persamaan linear agar dapat disimpan atau dikirim ke lokasi lain pada jaringan. Versi Avro yang diuji adalah versi 1.6.0 dan versi 1.7.6 yang dapat diunduh dari http://archive.apache.org/dist/ avro/. Pada pengujian ini, class dengan nama yang sama pada kedua proyek yang dibandingkan terlebih dahulu untuk melihat kualitas class yang sama pada versi proyek yang berbeda, kemudian dibandingkan juga secara keseluruhan class pada proyek untuk kedua versi yang berbeda tersebut untuk melihat kualitasnya secara keseluruhan. Jadi, total class yang sama untuk Avro 1.6.0 dan 1.7.6 adalah 42 class. Total class Avro 1.6.0 adalah 42 class dan Avro 1.7.6 adalah 78 class. Gambar 4 menunjukkan sebagian class diagram dari Avro versi 1.6.0.
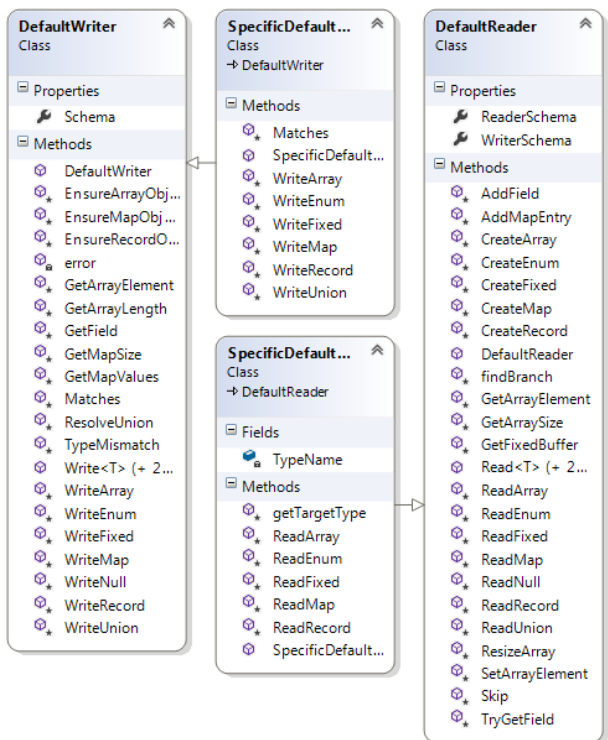

\section{Gambar 4. Sebagian Class Diagram dari Avro C\# API versi 1.6.0.}

Gambar 5 menunjukkan sebagian class diagram dari Avro versi 1.7.6.

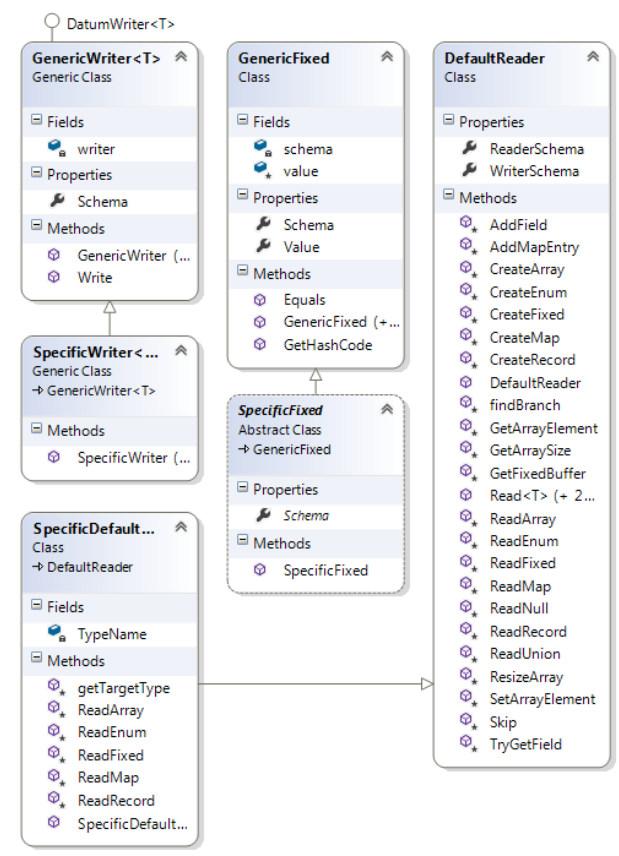

\section{Gambar 5. Sebagian Class Diagram dari Avro C\# API versi 1.7.6.}

Rangkuman hasil perhitungan metrik kualitas eksternal dari Avro C\# API versi 1.6.0 dan 1.7.6 untuk class yang sama 
dapat dilihat pada Tabel 2. Berdasarkan hasil yang diperoleh, kita dapat melihat nilai mininum dan maksimum yang sama untuk reusability dan efficiency pada kedua proyek. Namun, total reusability dan efficiency dari Avro 1.6.0 sedikit lebih tinggi dibandingkan dengan Avro 1.7.6. Hal ini berarti terjadinya penurunan kualitas reusability dan efficiency pada Avro 1.7.6 pada class yang sama. Namun, jika kita melihat secara keseluruhan class pada Avro 1.7.6 sebanyak 78 class, maka rata-rata nilai reusability yang diperoleh adalah 1.21067 dan rata-rata nilai efficiency adalah 2.23576. Nilai reusability Avro 1.7.6 secara keseluruhan lebih baik dari Avro 1.6.0 dengan selisih sebesar 0.02736 . Hal tersebut juga terjadi pada efficiency dengan selisih sebesar 0.04732. Jadi, secara keseluruhan Avro 1.7.6 mengalami peningkatan kualitas reusability dan efficiency dibandingkan dengan versi Avro 1.6.0.

Tabel 2. Hasil Pengukuran kualitas class yang sama pada Avro C\# API

\begin{tabular}{|c|c|c|c|}
\hline \multirow{2}{*}{\multicolumn{2}{|c|}{$\begin{array}{c}\text { Faktor Kualitas } \\
\text { Eksternal }\end{array}$}} & \multicolumn{2}{|c|}{ Versi Perangkat Lunak } \\
\hline & & \multirow{2}{*}{$\begin{array}{c}\text { Avro 1.6.0 } \\
0.8\end{array}$} & \multirow{2}{*}{$\begin{array}{c}\text { Avro 1.7.6 } \\
0.8\end{array}$} \\
\hline Reusability & Min & & \\
\hline & Max & 1.8 & 1.8 \\
\hline & Sum & 49.69901 & 47.99316 \\
\hline & Average & 1.18331 & 1.14269 \\
\hline \multirow[t]{4}{*}{ Efficiency } & Min & 1.4 & 1.4 \\
\hline & Max & 2.5 & 2.5 \\
\hline & Sum & 91.91439 & 91.73939 \\
\hline & Average & 2.18844 & 2.18271 \\
\hline
\end{tabular}

\section{KESIMPULAN}

Penelitian ini menghasilkan aplikasi pengukuran kualitas reusability dan efficiency dengan menggunakan nilai $\mathrm{CK}$ Metrics dan fuzzy inference system Mamdani. Aplikasi ini dapat memberikan informasi yang jelas mengenai kualitas dari class pada perangkat lunak berorientasi objek. Hasilnya berupa nilai kuantitatif dan kualitatif, sehingga dapat dengan mudah digunakan untuk melakukan perbandingan kualitas antara dua kode program yang memiliki fungsi yang sama dan memberikan panduan untuk pengembangan perangkat lunak versi berikutnya.

\section{Referensi}

[1] Laird, L. M. dan Brennan, M. C., 2006, Software Measurement and Estimation: A Practical Approach, edisi 1, John Wiley \& Sons, Inc.

[2] Cavano, J. P., dan McCall, J. A., 1978, A Framework for the Measurement of Software Quality, Proceedings of the Software Quality Assurance Workshop on Functional and Performance Issues, 133-139

[3] Chidamber, S. R., dan Kemerer, C. F., 1994, A Metric Suite for Object Oriented Design, IEEE Transactions on Software Engineering, vol 20, 476-493

[4] Mago, J. dan Kaur, P., 2012, Analysis of Quality of the Design of the Object Oriented Software using Fuzzy Logic, International Conference on Recent Advances and Future Trends in Information Technology (iRAFIT2012), vol 3, 21-25

[5] Stamelos, I., et al, 2002, Code Quality Analysis in Open Source Software Development, Information Systems Journal, vol 12, 43-60

[6] Mago, J., Kaur,S., dan Saurabh, K., 2012, Fuzzy Model to Analyze and Interpret Object Oriented Software Design, International Journal of Electrical, Electronics, and Computer, vol 1, 41-46.

[7] O’Docherty, M., 2005, Object-oriented Analysis \& Design Understanding System Development with UML 2.0, West Sussex, England: John Willey \& Sons.

[8] Kusumadewi, S., dan Purnomo, H., 2010, Aplikasi Logika Fuzzy untuk Pendukung Keputusan Ed. 2, Graha Ilmu. 